ENVIRONMENTAL EXPOSURE

\title{
Traffic related air pollution as a determinant of asthma among Taiwanese school children
}

\author{
B-F Hwang, Y-L Lee, Y-C Lin, J J K Jaakkola, Y L Guo
}

Thorax 2005;60:467-473. doi: 10.1136/thx.2004.033977

See end of article for authors' affiliations

.....................

Correspondence to:

Dr Y L Guo, Department of Environmental and

Occupational Health,

National Cheng Kung

University, Tainan,

Taiwan; leonguo@mail.

ncku.edu.tw

Received 27 August 2004

Accepted 3 February 2005

\begin{abstract}
Background: There is evidence that long term exposure to ambient air pollution increases the risk of childhood asthma, but the role of different sources and components needs further elaboration. To assess the effect of air pollutants on the risk of asthma among school children, a nationwide cross sectional study of 32672 Taiwanese school children was conducted in 2001.

Methods: Routine air pollution monitoring data for sulphur dioxide $\left(\mathrm{SO}_{2}\right)$, nitrogen oxides (NOx), ozone $\left(\mathrm{O}_{3}\right)$, carbon monoxide $(\mathrm{CO})$, and particles with an aerodynamic diameter of $10 \mu \mathrm{m}$ or less $\left(\mathrm{PM}_{10}\right)$ were used. Information on individual characteristics and indoor environments was from a parent administered questionnaire (response rate 93\%). The exposure parameters were calculated using the mean of the 2000 monthly averages. The effect estimates were presented as odds ratios (ORs) per $10 \mathrm{ppb}$ changes for $\mathrm{SO}_{2}$, $\mathrm{NOx}$, and $\mathrm{O}_{3}, 100 \mathrm{ppb}$ changes for $\mathrm{CO}$, and $10 \mu \mathrm{g} / \mathrm{m}^{3}$ changes for $\mathrm{PM}_{10}$.

Results: In a two stage hierarchical model adjusting for confounding, the risk of childhood asthma was positively associated with $\mathrm{O}_{3}$ (adjusted $\mathrm{OR} 1.138$, 95\% confidence interval (CI) 1.001 to 1.293), $\mathrm{CO}$ (adjusted OR 1.045, 95\% Cl 1.017 to 1.074), and NOx (adjusted OR 1.005, 95\% Cl 0.954 to 1.117 ). Against our prior hypothesis, the risk of childhood asthma was weakly or not related to $\mathrm{SO}_{2}$ (adjusted $\mathrm{OR}$ $0.874,95 \% \mathrm{Cl} 0.729$ to 1.054 ) and $\mathrm{PM}_{10}$ (adjusted $\mathrm{OR} 0.934,95 \% \mathrm{Cl} 0.909$ to 0.960 ).

Conclusions: The results are consistent with the hypothesis that long term exposure to traffic related outdoor air pollutants such as $\mathrm{NOx}, \mathrm{CO}$, and $\mathrm{O}_{3}$ increases the risk of asthma in children.
\end{abstract}

$\mathrm{T}$ here is a large worldwide variation in the prevalence of asthma in children and there is also evidence that the prevalence has been increasing. ${ }^{1}$ Both genetic and environmental factors play important roles in the aetiology of childhood asthma, and there is probably also genetic susceptibility to the effects of air pollution. ${ }^{2}$ Short term changes in the occurrence of asthma are more likely to be influenced by changes in the environment, diet, and lifestyle than by changes in the genetic pool. From a preventive perspective, information on environmental, dietary, and behavioural factors is crucial. ${ }^{3}$ Identification of indicators of genetic susceptibility to environmental exposures could be useful from the preventive point of view. There is evidence that long term exposure to ambient air pollution increases the risk of childhood asthma, but the role of different sources and components needs further elaboration. ${ }^{4-12}$

In a nationwide cross sectional study in Taiwan, Guo et al found an association between traffic related air pollution concentrations and the risk of asthma in school children. ${ }^{13}$ This study did not adjust for parental atopy or indoor exposures which are potential sources of confounding and effect modification. In 2001 we conducted a new nationwide cross sectional study in which we also collected information on these important potential determinants of allergic disease in children.

In the present study we have elaborated the relation between exposure to urban air pollution and the risk of asthma in school children, focusing on predominantly traffic related pollutants such as nitrogen oxides $(\mathrm{NOx})$, ozone $\left(\mathrm{O}_{3}\right)$, and carbon monoxide (CO). We also assessed the role of air pollutants, mainly from other fossil fuel combustion sources such as sulphur dioxide $\left(\mathrm{SO}_{2}\right)$, and particles with an aerodynamic diameter of $10 \mu \mathrm{m}$ or less $\left(\mathrm{PM}_{10}\right)$. Furthermore, we studied the joint effects of parental atopy and outdoor air pollution on the risk of asthma. Parental asthma, allergic rhinitis, and allergic atopic eczema were used as surrogates of the genes that are responsible for susceptibility to the effects of air pollutants on asthma. We applied a two stage hierarchical model to adjust for confounding and to elaborate effect modification at the individual level and to assess the effects of air pollution at the municipal level. ${ }^{14} 15$

\section{METHODS \\ Data collection and study population}

A nationwide cross sectional study was conducted in Taiwan in 2001 where a modified Chinese version of the International Study of Asthma and Allergies in Childhood (ISAAC-C) questionnaire was used to collect information on children's health, environmental exposures, and other relevant factors. ${ }^{16}$ The study population was recruited from elementary and middle schools in 22 municipalities within $1 \mathrm{~km}$ from Taiwan Environmental Protection Agency (EPA) air monitoring stations. The questionnaire was taken home by students and answered by parents. A total of 35036 children aged 6-15 years were approached. The response rate was $93.2 \%$. 2364 children were excluded because of an incomplete questionnaire, leaving a final study population of 32672 schoolchildren.

The study protocol was approved by the Respiratory Health Screening Steering Committee of the Taiwan Department of Health and the Institutional Review Board of National Cheng Kung University Hospital, and it complied with the principles outlined in the Helsinki Declaration. ${ }^{17}$

\section{Health outcome}

The outcome of interest was childhood asthma, which was defined on the basis of the answer to the question: "Has a physician ever diagnosed your child as having asthma?".

Abbreviations: $\mathrm{CO}$, carbon monoxide; $\mathrm{NOx}$, nitrogen oxides; $\mathrm{O}_{3}$, ozone; $\mathrm{PM}_{10}$, particles with aerodynamic diameter $10 \mu \mathrm{m}$ or less; $\mathrm{SO}_{2}$, sulphur dioxide 


\section{Exposure assessment}

Complete monitoring data for the air pollutants including sulphur dioxide $\left(\mathrm{SO}_{2}\right)$, nitrogen oxides $(\mathrm{NOx})$, ozone $\left(\mathrm{O}_{3}\right)$, carbon monoxide (CO), and particles with an aerodynamic diameter of $10 \mu \mathrm{m}$ or less $\left(\mathrm{PM}_{10}\right)$, as well as daily temperature and relative humidity, are available from 1994 for 22 EPA monitoring stations on Taiwan's main island (fig 1). Concentrations of each pollutant are measured continuously and reported hourly-CO by non-dispersive infrared absorption, $\mathrm{NOx}$ by chemiluminescence, $\mathrm{O}_{3}$ by ultraviolet absorption, $\mathrm{SO}_{2}$ by ultraviolet fluorescence, and $\mathrm{PM}_{10}$ by beta-gauge. Exposure parameters in the present study were annual average concentrations, calculated from the monthly averages of the year 2000. Forty four schools in Taiwan's 22 municipalities were investigated. Stratified sampling by grade was applied in each school. ${ }^{18}$

\section{Covariates}

Information on potential confounders was obtained from the parent administered questionnaire. The covariates in the present analyses included age, sex, parental atopy, parental education, maternal smoking history during pregnancy, environmental tobacco smoke (ETS), and visible mould (table 1). Parental atopy was a measure of genetic predisposition to asthma and it was defined as the father or mother of the index child ever having been diagnosed as having asthma, allergic rhinitis, or atopic eczema.

\section{Statistical methods}

The odds ratio (OR) was used as a measure of the relation between exposure to air pollution and the risk of childhood asthma. Adjusted ORs were estimated in a two stage hierarchical model using logistic and linear regression analyses. The models assume two sources of variation-the variation among subjects in the first stage, part of which could be explained by the individual characteristics, and the variation among municipalities in the second stage, part of which could be explained by variables measured at the

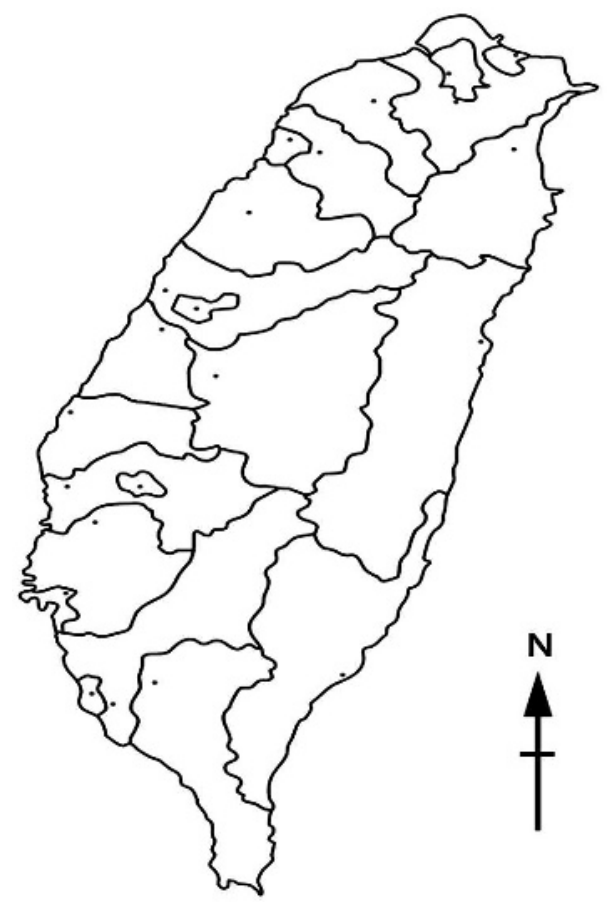

Figure 1 The 22 municipalities with selected air pollution monitoring stations in this study in Taiwan 2001. Circles indicate $1 \mathrm{~km}$ catchment area. municipal level. In the analyses we assumed that (1) the outcome variable follows Bernoulli distribution; (2) intercept terms are random at the municipal level; and (3) all the explanatory variables are fixed effects. A logistic regression model was fitted in the first stage for the risk of childhood asthma as a function of site-specific intercepts $\mathrm{j}$, where $\alpha \mathrm{j}=$ $1, \ldots, 22$, and personal covariates. The adjusted site-specific intercepts and prevalence rates are related by $\mathrm{Pj}=\mathrm{e}^{\alpha \mathrm{j}}$ / $\left(1+e^{\alpha j}\right)$. In the second stage these intercept terms representing the logit of the site-specific prevalence rates $(\mathrm{Pj} ; \mathrm{j}=1, \ldots$, 22 ), adjusted for personal covariates, were regressed on each site specific ambient pollutant level by using a linear "ecologic" regression-that is, logit $\alpha \mathrm{j}=\alpha+\mathrm{Uj}+\beta \mathrm{Zj}$ where Uj denotes the random departure from the general prevalence $\alpha \mathrm{j}$ on the logit scale for site $\mathrm{j}$ and $\mathrm{Zj}$ denotes the ambient pollution level for site $j$. Thus, $\beta$ can be interpreted as the $\log$ OR (per unit change) for each pollutant, adjusted for personal characteristics. The results from the models are presented as ORs, along with their $95 \%$ confidence intervals (CIs).

The goodness of fit was assessed with likelihood ratio tests (LR) to determine whether a variable contributed significantly to the model. Firstly, we fitted a full model with a complete set of covariates. To study further the sources of confounding we fitted models with different combinations of covariates and compared the effect from models with and without the covariate of interest. If the adjusted OR differed from the crude OR by more than $10 \%$, that covariate was be included in the final model. We first fitted one pollutant models and then considered two-pollutant models by fitting one traffic related and one stationary fossil fuel combustion related pollutant. Finally, we fitted two-pollutant models with $\mathrm{O}_{3}$ and another pollutant. The two-pollutant models provide estimates of the independent effects of $\mathrm{CO}, \mathrm{NOx}, \mathrm{SO}_{2}$, $\mathrm{PM}_{10}$, and $\mathrm{O}_{3}$ on childhood asthma, controlling for the second pollutant in the model. We also considered threepollutant models with one traffic related, one stationary fossil fuel combustion related pollutant, and $\mathrm{O}_{3}$. The effect of each pollutant on the risk of childhood asthma was presented as ORs per $10 \mathrm{ppb}$ changes for $\mathrm{SO}_{2}, \mathrm{NOx}$, and $\mathrm{O}_{3}, 100 \mathrm{ppb}$ changes for $\mathrm{CO}$, and $10 \mu \mathrm{g} / \mathrm{m}^{3}$ changes for $\mathrm{PM}_{10}$, along with their 95\% CIs. We assessed potential effect modification by parental atopy by comparing crude and adjusted effect estimates for children with and without atopic parents. The two-stage hierarchical model was used not only to derive more precise estimates of site specific parameters and site level effects, but also to adjust for multiple comparisons. ${ }^{19}$

\section{RESULTS}

Study population and occurrence of childhood asthma The characteristics of the study population and the prevalence of childhood asthma according to the covariates are shown in table 1 . The prevalence of asthma was 6.86\% (95\% CI 6.59 to 7.13 ). The prevalence of childhood asthma was related to young age, high level of parental education, male sex, parental atopy, maternal smoking during pregnancy and the presence of cockroaches and visible mould in the home. The prevalence of asthma was lower in children exposed to environmental tobacco smoke (ETS) than in those not exposed.

\section{Air pollution}

The distributions of the annual mean air pollutant concentrations, temperature, and relative humidity in the 22 monitoring stations in the year 2000 are presented in table 2 and the correlations between different pollutants are shown in table 3. The correlation between NOx and CO concentrations was high (0.88), which reflects the common source of motor vehicles. The concentrations of $\mathrm{PM}_{10}$ and $\mathrm{SO}_{2}$ were 
Table 1 Number of asthma cases, prevalence of asthma, and odds ratios (ORs) of asthma with $95 \%$ confidence interval $(95 \% \mathrm{Cl})$ by age, parental education, parental atopy, environmental tobacco smoke, maternal smoking during pregnancy, cockroaches, water damage, and visible mould in Taiwan 2001

\begin{tabular}{|c|c|c|c|c|}
\hline Determinant & No of children & $\begin{array}{l}\text { No with physician } \\
\text { diagnosed asthma }\end{array}$ & $\begin{array}{l}\text { Prevalence } \\
(\%)\end{array}$ & OR $(95 \% \mathrm{Cl})$ \\
\hline \multirow{2}{*}{\multicolumn{5}{|c|}{ Age (years) }} \\
\hline & & & & \\
\hline$\leqslant 7$ & 4692 & 349 & 7.44 & 1.34 (1.09 to 1.64 ) \\
\hline 8 & 3559 & 251 & 7.05 & $1.26(1.02$ to 1.57$)$ \\
\hline 9 & 3582 & 268 & 7.48 & 1.35 (1.09 to 1.67$)$ \\
\hline 10 & 3760 & 290 & 7.71 & 1.39 (1.13 to 1.72$)$ \\
\hline 11 & 3539 & 238 & 6.73 & $1.20(0.97$ to 1.49$)$ \\
\hline 12 & 3809 & 273 & 7.17 & $1.29(1.04$ to 1.59$)$ \\
\hline 13 & 3730 & 240 & 6.43 & 1.15 (0.92 to 1.42$)$ \\
\hline 14 & 3634 & 198 & 5.45 & $0.96(0.77$ to 1.20$)$ \\
\hline 15 & 2367 & 134 & 5.66 & 1.00 \\
\hline \multicolumn{5}{|l|}{ Sex } \\
\hline Male & 16540 & 1340 & 8.10 & 1.49 (1.37 to 1.63$)$ \\
\hline Female & 16132 & 901 & 5.59 & 1.00 \\
\hline \multicolumn{5}{|c|}{$\begin{array}{l}\text { Parental education } \\
\text { (years) }\end{array}$} \\
\hline$<6$ & 1831 & 74 & 4.04 & 1.00 \\
\hline $6-8$ & 5725 & 269 & 4.70 & 1.17 (0.90 to 1.52$)$ \\
\hline $9-11$ & 14749 & 937 & 6.35 & $1.61(1.26$ to 2.05$)$ \\
\hline$\geqslant 12$ & 10367 & 961 & 9.27 & $2.43(1.90$ to 3.09$)$ \\
\hline \multicolumn{5}{|c|}{ Parental atopy* } \\
\hline No & 22761 & 1083 & 4.76 & 1.00 \\
\hline \multirow{2}{*}{\multicolumn{5}{|c|}{$\begin{array}{l}\text { Environmental } \\
\text { tobacco smoke* }\end{array}$}} \\
\hline & & & & \\
\hline No & 13212 & 990 & 7.49 & 1.00 \\
\hline Yes & 19229 & 1232 & 6.41 & 0.85 (0.78 to 0.92$)$ \\
\hline \multicolumn{5}{|c|}{$\begin{array}{l}\text { Maternal smoking } \\
\text { during pregnancy* }\end{array}$} \\
\hline No & 31791 & 2168 & 6.82 & 1.00 \\
\hline Yes & 706 & 56 & 7.93 & 1.18 (0.89 to 1.56$)$ \\
\hline \multicolumn{5}{|c|}{$\begin{array}{l}\text { Cockroaches noted } \\
\text { monthly* }\end{array}$} \\
\hline No & 6663 & 410 & 6.15 & 1.00 \\
\hline Yes & 25507 & 1796 & 7.04 & 1.15 (1.03 to 1.29$)$ \\
\hline \multicolumn{5}{|c|}{ Water damage ${ }^{*}$} \\
\hline No & 29845 & 2055 & 6.89 & 1.00 \\
\hline Yes & 2667 & 176 & 6.60 & $0.96(0.81$ to 1.12$)$ \\
\hline \multicolumn{5}{|l|}{ Visible mould* } \\
\hline No & 24308 & 1581 & 6.50 & 1.00 \\
\hline Yes & 7573 & 616 & 8.13 & $1.27(1.16$ to 1.40$)$ \\
\hline
\end{tabular}

also highly correlated (0.58), indicating a common source of stationary fuel combustion, although $\mathrm{SO}_{2}$ concentrations were also correlated with both traffic related pollutants. The concentration of $\mathrm{O}_{3}$ was negatively correlated with the mainly traffic related pollutants but positively correlated with $\mathrm{PM}_{10}$ and $\mathrm{SO}_{2}$, and it was only weakly correlated with that of traffic related and stationary fossil fuel combustion related air pollutants.

\section{Air pollution and childhood asthma}

In the one-pollutant model, the risk of asthma was not related to NOx levels (adjusted OR 1.005 per 10 ppb change
(95\% CI 0.945 to 1.060$)$ ). Addition of either $\mathrm{SO}_{2}$ (adjusted OR 1.048 (95\% CI 0.983 to 1.117 )) or $\mathrm{PM}_{10}$ (adjusted OR 1.065 (95\% CI 1.009 to 1.123$)$ ) increased the effect estimate for NOx substantially, and addition of $\mathrm{O}_{3}$ (adjusted OR 1.029 (95\% CI 0.973 to 1.089$)$ ) slightly (table 4 ). In the threepollutant model the estimates for NOx were 1.113 (95\% CI 1.038 to 1.194$)$ and 1.152 (95\% CI 1.082 to 1.227$)$, respectively, when $\left(\mathrm{SO}_{2}\right.$ and $\left.\mathrm{O}_{3}\right)$ or $\left(\mathrm{PM}_{10}\right.$ and $\left.\mathrm{O}_{3}\right)$ were added and showed statistical significances (table 5). The adjusted OR for $100 \mathrm{ppb}$ change in CO was 1.045 (95\% CI 1.017 to 1.074 ) and the estimates changed little when a second or third pollutant was added. The adjusted OR for a

Table 2 Mean and distribution of 2000 annual air pollution and meteorology data from 22 monitoring stations in Taiwan

\begin{tabular}{|c|c|c|c|c|c|c|c|}
\hline & Mean (SD) & Minimum & $\begin{array}{l}\text { 25th } \\
\text { percentile }\end{array}$ & Median & $\begin{array}{l}\text { 75th } \\
\text { percentile }\end{array}$ & $\begin{array}{l}\text { Interquartile } \\
\text { range* }^{*}\end{array}$ & Maximum \\
\hline $\mathrm{CO}(\mathrm{ppb})$ & $664(153)$ & 416 & 540 & 647 & 752 & 212 & 964 \\
\hline NOx (ppb) & $27.64(8.38)$ & 10.88 & 21.47 & 33.07 & 29.58 & 11.60 & 43.98 \\
\hline $\mathrm{O}_{3}(\mathrm{ppb})$ & $23.14(3.25)$ & 18.65 & 20.34 & 25.20 & 22.69 & 4.86 & 31.17 \\
\hline $\mathrm{PM}_{10}\left(\mu \mathrm{g} / \mathrm{m}^{3}\right)$ & $55.58(16.57)$ & 29.36 & 42.96 & 53.81 & 70.37 & 27.41 & 99.58 \\
\hline $\mathrm{SO}_{2}(\mathrm{ppb})$ & $3.53(2.00)$ & 0.35 & 1.96 & 3.34 & 4.84 & 2.88 & 10.12 \\
\hline Temperature ( ${ }^{\circ} \mathrm{C}$ ) & $23.65(0.75)$ & 22.36 & 23.20 & 23.50 & 24.17 & 1.17 & 25.27 \\
\hline Relative humidity (\%) & $74.0(3.0)$ & 69.0 & 72.2 & 74.1 & 76.5 & 4.3 & 80.0 \\
\hline
\end{tabular}


Table 3 Correlations of air pollutants across 22 municipalities

\begin{tabular}{llllll}
\hline & $\mathrm{CO}$ & $\mathrm{NOx}$ & $\mathrm{O}_{3}$ & $\mathrm{PM}_{10}$ & $\mathrm{SO}_{2}$ \\
\hline $\mathrm{CO}$ & 1.00 & $0.88^{*}$ & -0.37 & 0.27 & 0.40 \\
$\mathrm{NOx}$ & 1.00 & -0.39 & 0.34 & $0.50^{*}$ \\
$\mathrm{O}_{3}$ & & 1.00 & 0.28 & 0.19 \\
$\mathrm{PM}_{10}$ & & & 1.00 & $0.58^{*}$ \\
$\mathrm{SO}_{2}$ & & & & 1.00 \\
\hline${ }^{*}$ Correlation is significant at the 0.05 level. & & & \\
\hline
\end{tabular}

$10 \mathrm{ppb}$ change in $\mathrm{SO}_{2}$ alone was 0.874 (95\% CI 0.729 to 1.054 ), but inclusion of either of the traffic related pollutants reduced the effect estimate substantially whereas addition of $\mathrm{O}_{3}$ had little influence. The risk of childhood asthma was not related to $\mathrm{PM}_{10}$ concentrations in any combination of air pollutants. The risk of asthma was significantly related to $\mathrm{O}_{3}$ in the one-pollutant model (OR 1.138 (95\% CI 1.001 to 1.293)) and the addition of other pollutants increased the risk estimates further.

In summary, positive statistically significant associations were found for $\mathrm{O}_{3}$ and traffic related pollutants ( $\mathrm{CO}$ and $\mathrm{NOx}$ ). In contrast, negative or weak associations were found for $\mathrm{SO}_{2}$ and $\mathrm{PM}_{10}$.

In order to elaborate the potential effect modification, we systematically conducted stratified analyses in categories of parental atopy. The stratified analyses did not indicate any major effect modification (table 6).

\section{DISCUSSION}

The risk of childhood asthma increased according to increased annual levels of the two traffic related pollutants NOx and CO, as well as $\mathrm{O}_{3}$. The risk of asthma was not related to the levels of $\mathrm{PM}_{10}$ and $\mathrm{SO}_{2}$ and, in multi-pollutant models, the risk of asthma was negatively associated with the levels of $\mathrm{SO}_{2}$. The results did not provide evidence that hereditary atopy representing a genetic predisposition modifies the effects of exposure to outdoor air pollutants.

\section{Validity of results}

Routine air pollution monitoring data were used as the basis for exposure assessment. These data represented reasonably well exposures both in the school and in the home for two reasons. The schools were chosen to be in the vicinity of the monitoring stations. Almost all the children attended schools within $1 \mathrm{~km}$ of their homes because the density of elementary and middle schools in Taiwan is very high. Finally, the two-stage hierarchical modelling took into account the fact that municipal level exposure information was used. Although we did not collect information about the vicinity of the busy road, the present study and previous studies from German ${ }^{20}$ and Mexican cities ${ }^{21}$ provide consistent evidence that the outdoor $\mathrm{NO}_{2}$ level is a better predictor of traffic exposure than exposure to $\mathrm{NO}_{2}$ at the personal level.

From previous literature we know that a high proportion of traffic related outdoor air pollutants (NOx, CO) penetrate indoors, but the penetration proportion for particles is lower when mechanical filtration or an air conditioner is used. ${ }^{22-24}$ Most of the Taiwanese school children spend at least 8 hours/ day in school. Air conditioning is rare in Taiwanese classrooms. Mechanical filtration is practically the only type of filtration in Taiwanese homes during the summer, even if the home is air conditioned. Any known or unknown factors such as air change, penetration, deposition, as well as emission strengths for indoor pollutants could be responsible for the observed association between personal exposure and municipal level exposure. This was a common problem in all the previous studies assessing the effects of air pollution on the risk of asthma in school children.
In cross sectional studies, selection bias is a potential threat to validity. A plausible mechanism of selection is that parents of children with asthma move to residential areas with lower levels of air pollution which will lead to underestimation of the relation between exposure and outcome. Any random migration is likely to result in underestimation of the air pollution effects but would not introduce a positive bias in the associations. Information on residential history in a cross sectional study could be used to reduce the possibility of selection bias, whereas a longitudinal study would provide a stronger design for minimising this problem. We did not have sufficient information on children's residential history to formally assess the lifetime exposure to air pollution, so current exposure was used as the proxy of previous exposure. Most of the studies to date on the relationship between exposure to air pollutants and risk of asthma in children have been cross sectional. ${ }^{7-12}$

In our statistical analyses we controlled for a number of potential individual level confounders such as parental education and indoor environmental exposures. In stratified analyses on different levels of covariates, we studied the possibility of residual confounding. Parental education had a positive association with concentrations of traffic related pollutants. The prevalence of childhood asthma was also positively associated with the level of parental education, which could be explained by both the influence of air pollution and better access to health care.

Assessment of the independent effects of different pollutants is difficult because urban air pollution constitutes a complex mixture of several compounds. Although all the measured pollutants have several sources, $\mathrm{NOx}$ and $\mathrm{CO}$ are predominantly from vehicle emissions while $\mathrm{SO}_{2}$ and $\mathrm{PM}_{10}$ are mainly from stationary fossil combustion processes. ${ }^{25}{ }^{26}$ In the present study, NOx and CO concentrations were highly correlated, indicating the common source of motor vehicle traffic emissions. $\mathrm{SO}_{2}$ and $\mathrm{PM}_{10}$ concentrations were also correlated, their common sources being stationary fossil fuel combustion. In the modelling, we were able to control for one stationary fossil fuel pollutant at a time as a potential confounder when assessing the effect of one of the traffic related pollutants and vice versa. Due to collinearity problems, it was not possible to separate the impact of traffic related pollutants ( $\mathrm{NOx}$ and $\mathrm{CO}$ ) from each other.

\section{Synthesis with previous knowledge}

The results of the present study are in line with several previous studies from Seattle, ${ }^{4}$ Illinois, ${ }^{5}$ Los Angeles, ${ }^{6}$ Austria, ${ }^{7}$ the Netherlands, ${ }^{8}$ Czech Republic and Poland, ${ }^{9}$ Germany, ${ }^{10}$ Japan, ${ }^{11}$ and China ${ }^{12}$ indicating that exposure to outdoor air pollutants increases the risk of asthma. All available studies suggest an increased risk for traffic related air pollutants $(\mathrm{CO} \text { and } \mathrm{NOx})^{4-811} 12$ and $\mathrm{O}_{3}{ }^{56}$ but the findings are inconsistent for stationary fossil fuel combustion related air pollutants $\left(\mathrm{SO}_{2}\right.$ and $\left.\left.\mathrm{PM}_{10}\right)\right)^{9}{ }^{10} 12$

A panel study conducted in Seattle showed no association between exposure to $\mathrm{CO}$ and the occurrence of asthma related symptoms. ${ }^{4}$ In a cross sectional study carried out in Illinois, increased morning and evening asthma symptom 


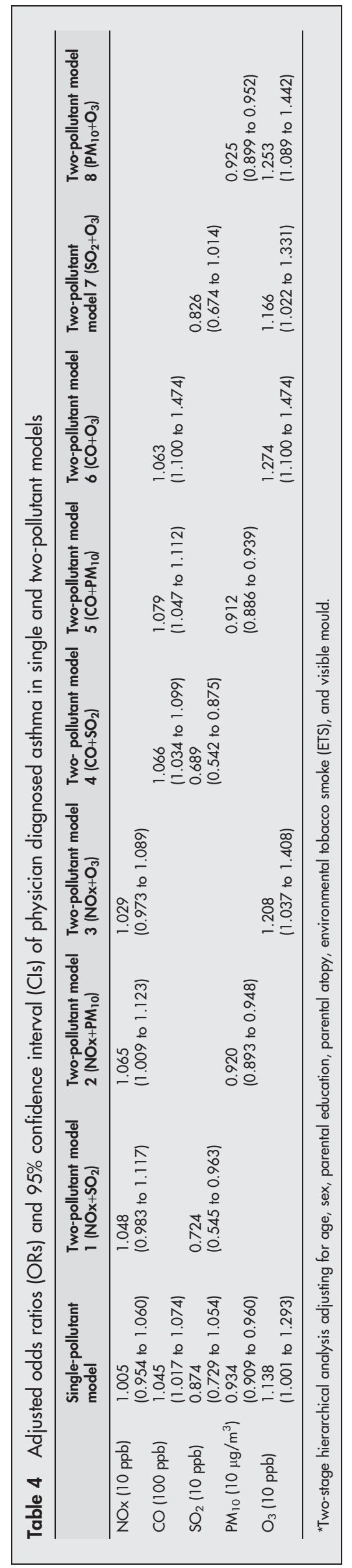

scores were associated with the levels of $\mathrm{O}_{3} .{ }^{5}$ A population based cross sectional study in Los Angeles found positive associations between asthma symptoms and all the US criteria air pollutants $\left(\mathrm{O}_{3}, \mathrm{NO}_{2}, \mathrm{SO}_{2}, \mathrm{PM}_{10}\right)$. The risk of more severe asthma symptoms was associated with 8 hour exposure to $\mathrm{NO}_{2}$ levels above $1.4 \mathrm{ppb}$ (OR 1.27, 95\% CI 1.05 to 1.54). ${ }^{6}$ Four recent studies from Austria, the Netherlands, Japan, and China examined the relationship between exposure to $\mathrm{NO}_{2}$ and the risk of childhood asthma. ${ }^{7811}{ }^{12}$ In the Austrian study, the risk of childhood asthma was associated with $\mathrm{NO}_{2}$ levels (highest $v$ lowest category, prevalence odds ratio (POR) 5.81, 95\% CI 1.27 to 26.5$){ }^{7}$ In a cohort study conducted in the Netherlands, the risk of physician diagnosed asthma was associated with traffic related air pollution measured as $\mathrm{NO}_{2}$ concentrations. ${ }^{8} \mathrm{~A}$ survey in Japan found that a $10 \mathrm{ppb}$ increase in the outdoor $\mathrm{NO}_{2}$ concentration was associated with an increased risk of asthma with an adjusted OR of 2.10 (95\% CI 1.10 to 4.75$).{ }^{11} \mathrm{~A}$ study conducted in four Chinese cities suggested a positive association between the risk of childhood asthma and the levels of $\mathrm{PM}_{10}$ (OR 1.33, 95\% CI 0.80 to 2.19), but weak or negative associations were found for $\mathrm{SO}_{2}(\mathrm{OR} 1.03,95 \% \mathrm{CI}$ 0.75 to 1.41 ) and NOx (OR $0.95,95 \%$ CI 0.63 to 1.43 ). ${ }^{12}$ In the Czech and Polish study the lifetime prevalence of physician diagnosed asthma in schoolchildren was associated with $\mathrm{SO}_{2}$ (OR 1.39 per $50 \mu \mathrm{g} / \mathrm{m}^{3}$ increase in $\mathrm{SO}_{2}, 95 \%$ CI 1.10 to 1.92 ). ${ }^{9}$ In contrast, a study in Germany indicated that high levels of $\mathrm{SO}_{2}$ in East Germany were associated with a lower prevalence of asthma compared with West Germany. ${ }^{10}$

Nitrogen dioxide has been shown to be an acute respiratory irritant in controlled exposure studies. ${ }^{27}$ There are no plausible mechanisms through which $\mathrm{CO}$ exposure would influence the airways and increase the risk of childhood asthma. Both NOx and CO represent the complex mixture of traffic exhaust, and $\mathrm{NO}_{2}$ is known to be the best indicator of motor vehicle traffic emissions. In the present study it was not possible to determine to what extent NOx would have direct effects on children's airways. CO is unlikely to have any direct effects on the airways.

A positive association between the risk of childhood asthma and exposure to $\mathrm{O}_{3}$ was identified, compatible with toxicological studies. ${ }^{28}{ }^{29}$ The prevalence of childhood asthma was associated with $\mathrm{O}_{3}$ levels. The effect was increased when adjusting for either a traffic related pollutant, stationary fossil fuel pollutant, or both. Ozone is a secondary pollutant in the atmosphere produced from traffic exhausts, but scavenged by direct motor vehicle emissions. It is a known respiratory irritant ${ }^{30}$ and could be causally related to childhood asthma.

Our finding of a lack of association between the risk of childhood asthma and $\mathrm{PM}_{10}$ levels is consistent with the results from the Harvard 24 Cities Study in North America. ${ }^{31}$ Although the risk of childhood asthma was not related to the levels of $\mathrm{PM}_{10}$, it is likely that there is an association with fine particulate matter $\left(\mathrm{PM}_{2.5}\right)$ and ultrafine particles typically present in motor vehicle exhausts and, in particular, in diesel exhausts. Further studies should assess these relations. No association between childhood asthma and $\mathrm{SO}_{2}$ was found in the present study, possibly because the average level of combustion related air pollutants such as $\mathrm{SO}_{2}$ in Taiwan is substantially lower than levels reported in studies in the Czech Republic and Poland ${ }^{9}$ and in East Germany. ${ }^{10}$

\section{Conclusion}

The present study provides additional evidence that exposure to outdoor air pollutants increases the risk of childhood asthma in school children. The observed relations between the risk of childhood asthma and NOx and CO levels suggests that emissions from motor vehicles play an important role. In 
Table 5 Adjusted odds ratios (ORs) and 95\% confidence interval (Cls) of physician-diagnosed asthma in three-pollutant models

\begin{tabular}{|c|c|c|c|c|}
\hline & $\begin{array}{l}\text { Three-pollutant model } 1 \\
\left(\mathrm{NOx}+\mathrm{SO}_{2}+\mathrm{O}_{3}\right)\end{array}$ & $\begin{array}{l}\text { Three-pollutant model } 2 \\
\left(\mathrm{NOx}+\mathrm{PM}_{10}+\mathrm{O}_{3}\right)\end{array}$ & $\begin{array}{l}\text { Three-pollutant model } 3 \\
\left(\mathrm{CO}+\mathrm{SO}_{2}+\mathrm{O}_{3}\right)\end{array}$ & $\begin{array}{l}\text { Three-pollutant model } 4 \\
\left(\mathrm{CO}+\mathrm{PM}_{10}+\mathrm{O}_{3}\right)\end{array}$ \\
\hline $\mathrm{NOx}(10 \mathrm{ppb})$ & $1.113(1.038$ to 1.194$)$ & $1.152(1.082$ to 1.227$)$ & & \\
\hline $\mathrm{CO}(100 \mathrm{ppb})$ & & & $1.111(1.074$ to 1.150$)$ & $1.119(1.084$ to 1.155$)$ \\
\hline $\mathrm{SO}_{2}(10 \mathrm{ppb})$ & $0.585(0.433$ to 0.791$)$ & & $0.528(0.405$ to 0.688$)$ & \\
\hline $\mathrm{PM}_{10}\left(10 \mu \mathrm{g} / \mathrm{m}^{3}\right)$ & & $0.888(0.858$ to 0.918$)$ & & $0.886(0.859$ to 0.914$)$ \\
\hline $\mathrm{O}_{3}(10 \mathrm{ppb})$ & $1.360(1.152$ to 1.604$)$ & 1.501 (1.274 to 1.768 ) & $1.500(1.273$ to 1.767$)$ & $1.587(1.351$ to 1.865$)$ \\
\hline
\end{tabular}

Table 6 Crude and adjusted odds ratios (ORs) with $95 \%$ confidence interval (Cls) of physician diagnosed asthma stratified by parental atopy in the relation between childhood asthma and air pollutants

\begin{tabular}{llll}
\hline & Parental atopy & $\begin{array}{l}\text { Crude OR } \\
(95 \% \mathrm{Cl})\end{array}$ & $\begin{array}{l}\text { Adjusted OR } \\
(95 \% \mathrm{Cl})^{*}\end{array}$ \\
\hline $\mathrm{NO} \times(10 \mathrm{ppb})$ & Yes & $1.00(0.93$ to 1.08$)$ & $0.99(0.92$ to 1.07$)$ \\
$\mathrm{CO}(100 \mathrm{ppb})$ & $\mathrm{No}$ & $1.04(0.97$ to 1.13$)$ & $1.02(0.95$ to 1.10$)$ \\
& Yes & $1.05(1.01$ to 1.09$)$ & $1.04(1.00$ to 1.08$)$ \\
$\mathrm{SO}_{2}(10 \mathrm{ppb})$ & $\mathrm{No}$ & $1.08(1.04$ to 1.12$)$ & $1.06(1.02$ to 1.10$)$ \\
& Yes & $0.76(0.55$ to 1.06$)$ & $0.86(0.62$ to 1.21$)$ \\
$\mathrm{PM}_{10}\left(10 \mu \mathrm{g} / \mathrm{m}^{3}\right)$ & No & $0.70(0.51$ to 0.95$)$ & $0.77(0.56$ to 1.07$)$ \\
$\mathrm{O}_{3}(10 \mathrm{ppb})$ & Yes & $0.93(0.89$ to 0.96$)$ & $0.94(0.90$ to 0.98$)$ \\
& Yo & $0.90(0.87$ to 0.94$)$ & $0.92(0.89$ to 0.96$)$ \\
& Yes & $1.09(0.89$ to 1.33$)$ & $1.15(0.93$ to 1.42$)$ \\
\hline
\end{tabular}

*Two-stage hierarchical analysis adjusting for age, sex, parental education, environmental tobacco smoke (ETS), and visible mould.

addition, the relationship with $\mathrm{O}_{3}$ levels indicates that photochemical air pollution contributes to adverse health effects.

\section{Authors' affiliations}

B-F Hwang, Department of Health Care Administration, Diwan College of Management, Tainan, Taiwan; and Department of Environmental and Occupational Health, College of Medicine, National Cheng Kung University, Tainan, Taiwan

Y-L Lee, Y L Guo, Department of Environmental and Occupational Health, College of Medicine, National Cheng Kung University, Tainan, Taiwan; and Department of Internal Medicine, National Cheng Kung University Hospital, Tainan, Taiwan

Y-C Lin, College of Dental Medicine, Kaohsiung Medical University, Kaohsiung, Taiwan

J J K Jaakkola, Institute of Occupational and Environmental Medicine, University of Birmingham, Birmingham, UK

This study was partially supported by grant \#NSC92-2302-B-006-028 from the National Science Council and grant \#DOH90-TD-1138 from the Department of Health. Yung-Ling Lee was also a recipient of the Taiwan National Health Research Institute MD-PhD Predoctoral Fellowship (DD9102N). Jouni Jaakkola was partly supported by The Yrjo Jahnsson Foundation.

\section{REFERENCES}

1 International Study of Asthma and Allergies in Childhood (ISAAC) Steering Committee. Worldwide variation in prevalence of symptoms of asthma, allergic rhinoconjunctivitis and atopy eczema: ISAAC. Lancet 1998;351:1225-32.

2 Kauffmann F, Dizier MH, Annesi-Maesano I, et al. EGEA (Epidemiological study on the Genetic and Environment of Asthma, Bronchial Hyperresponsiveness and Atopy)-descriptive characteristics. Clin Exp Allergy 1999;29(Suppl 4):17-21.

3 D'Amato G. Outdoor air pollution, climate and allergic respiratory disease: evidence of a link. Clin Exp Allergy 2000;32:1391-3.

4 Yu O, Sheppard L, Lumley T, et al. Effects of ambient air pollution on symptoms of asthma in Seattle-area children enrolled in the CAMP study. Environ Health Perspect 2000;108:1209-14.
5 Ross MA, Persky VW, Scheff PA, et al. Effect of ozone and aeroallergens on the respiratory health of asthmatics. Arch Environ Health 2002;57:568-78.

6 Delfino RJ, Gong H Jr, Linn WS, et al. Asthma symptoms in Hispanic children and daily ambient exposures to toxic and criteria air pollutants. Environ Health Perspect 2003;111:647-56.

7 Studnicka M, Hackl E, Pischinger J, et al. Traffic-related $\mathrm{NO}_{2}$ and the prevalence of asthma and respiratory symptoms in seven years olds. Eur Respir J 1997; 10:2275-8.

8 Brauer M, Hoek G, Van Vliet P, et al. Air pollution from traffic and development of respiratory infections and asthmatic and allergic symptoms in children. Am J Respir Crit Care Med 2002;166:1092-8.

9 Pikhart H, Bobak M, Gorynski P, et al. Outdoor sulphur dioxide and respiratory symptoms in Czech and Polish school children: a small-area study (SAVIAH). Int Arch Occup Environ Health 2001;74:574-8.

10 von Mutius E, Martinez FD, Fritzsch C, et al. Prevalence of asthma and atopy in two areas of West and East Germany. Am J Respir Crit Care Med 1994; 149:358-64.

11 Shima M, Motoaki A. Effect of outdoor and indoor nitrogen dioxide on respiratory symptoms in schoolchildren. Int J Epidemiol 2000;29:862-70.

12 Zhang J, Hu W, Wei F, et al. Children's respiratory morbidity prevalence in relation to air pollution in four Chinese cities. Environ Health Perspect 2002;110:961-7.

13 Guo YL, Lin YC, Sung FC, et al. Climate, traffic-related air pollutants, and asthma prevalence in middle-school children in Taiwan. Environ Health Perspect 1999;107:1001-6.

14 Dominici F. Air pollution and health: what can we learn from a hierarchical approach? Am J Epidemiol 2002;155:11-5.

15 Greenland S. Principles of multilevel modeling. Int J Epidemiol 2000;29:158-67.

16 Asher MI, Keil U, Anderson HR, et al. International study of asthma and allergies in childhood (ISAAC): rationale and methods. Eur Respir J 1995;8:483-91.

17 World Medical Assembly. Declaration of Helsinki: Recommendations guiding physicians in biomedical research involving human subjects. Bull Pan Am Health Organ 1990;24:606-9.

18 Witte JS, Greenland S, Kim LL, et al. Multilevel modeling in epidemiology with GLIMMIX. Epidemiology 2000;11:684-8.

19 Lee YL, Lin YC, Hsive TR, et al. Indoor/outdoor environmental exposure, parental atopy and childhood asthma. Pediatrics 2003;112:e389-95.

20 Kramer U, Koch T, Ranft U, et al. Traffic-related air pollution is associated with atopy in children living in urban areas. Epidemiology 2000;1 1:64-70.

21 Ramirez-Aguilar M, Cicero-Fernandez P, Winer AM, et al. Measurements of personal exposure to nitrogen dioxide in four Mexican cities in 1996. J Air Waste Manag Assoc 2002;52:50-7.

22 Cyrys J, Pitz M, Bischof W, et al. Relationship between indoor and outdoor levels of fine particles mass, particle number concentrations and black smoke 
under different ventilation conditions. J Expos Anal Environ Epidemiol 2004; 14:275-83

23 Partti-Pellinen K, Marttila O, Ahonen A, et al. Penetration of nitrogen oxides and particles from outdoor into indoor air and removal of the pollutants through filtration of incoming air. Indoor Air 2002;10:126-32.

24 Rojas-Bracho L, Suh HH, Oyola P, et al. Measurement of children's exposures to particles and nitrogen dioxide in Santiago, Chile. Sci Total Environ 2000;287:249-64.

25 Ko YC. Air pollution and its health effects on residents in Taiwanese communities. Kaohsiung J Med Sci 1996;12:657-69.

26 Lee YL, Shaw CK, Su HJ, et al. Climate, traffic-related air pollutants and allergic rhinitis prevalence in middle-school children in Taiwan. Eur Respir J 2003;21:964-70.
27 Wang JH, Devalia JL, Duddle JM, et al. Effect of six-hour exposure to nitrogen dioxide on early-phase nasal response to allergen challenge in patients with a history of seasonal allergic rhinitis. J Allergy Clin Immunol 1995;96:669-76.

28 Matsumura $Y$. The effect of ozone, nitorogen dioxide, and sulfur dioxide on the experimentally induced allergic respiratory disorders in guinea pigs. Am Rev Respir Dis 1970;102:430-47.

29 Peden DB. Pollutants and asthma: role of air toxics. Environ Health Perspect 2002;11(Suppl 4):565-8.

30 Brunekreef B, Holgate ST. Air pollution and health. Lancet 2002;360:1233-42.

31 Dockery DW, Cunningham J, Damokosh Al, et al. Health effects of acid aerosols on North American children: respiratory symptoms. Environ Health Perspect 1996;104:500-5

\section{LUNG ALERT}

Further evidence on the dangers of exposure to second hand tobacco smoke

$\Delta$ Vineis $\mathrm{P}$, Airoldi L, Veglia F, et al. Environmental tobacco smoke and risk of respiratory cancer and chronic obstructive pulmonary disease in former smokers and never smokers in the EPIC prospective study. BMJ 2005;330:277-80

$\Delta$ McGhee SM, Ho YS, Schooling M, et al. Mortality associated with passive smoking in Hong Kong. BMJ 2005;330:287-8

$\mathrm{V}$

ineis et al report a prospective case-control study examining 123479 "healthy" never smokers or former smokers. Over 7 years of follow up, cases were defined as "respiratory cancers" or deaths from COPD. Controls were well matched. Information about tobacco smoke exposure and a thorough list of confounders was obtained by questionnaire at recruitment. This strengthens the study by cutting out recall bias. Follow up data were from multiple sources. A subset of subjects and controls were tested for the presence of genetic polymorphisms implicated in carcinogenesis.

Exposure to tobacco smoke was associated with increased risk of death from respiratory cancers/COPD (hazard ratio (HR) 1.30, 95\% CI 0.87 to 1.95) and lung cancer alone (HR 1.34, 0.85 to 2.13 ). The effect was significantly greater for exposure at work (HR for lung cancer $1.65,1.04$ to 2.63 ) than at home (HR 1.03, 0.60 to 1.76) and for former smokers than for never smokers. Work exposure may have been higher than at home but exposure was not quantified and only measured at one point in time. The authors postulate that the greater effect in former smokers may be due to genetic mutations already accrued. The case for causality is strengthened as genetic polymorphisms increase the susceptibility to smoke: odds ratio (OR) for lung cancer increased from 1.33 to 2.86 between the presence of one or two versus three or more risk polymorphisms. Self-reported exposure to smoke in childhood showed a clear dose-response effect in never smokers. Daily exposure for many hours as a child increased the HR for lung cancer in adulthood from 1.0 to 3.63 (1.19 to 11.11).

McGhee et al report a retrospective case-control study. Cases were identified from all deaths reported amongst never smokers, and those reporting the death completed a questionnaire about the deceased. Second hand smoke exposure was classified by the number of smokers who lived with the deceased $(0,1,2$ or more). There was no attempt to further quantify exposure. This retrospective nature risks recall bias and the only confounder controlled for was education, a proxy of social class. There was a $34 \%$ increase in all cause mortality with any exposure to second hand smoke. Importantly, there was a significant dose-dependent association between second hand smoke and mortality from lung cancer (OR 1.74, 1.06 to 2.86 comparing no exposure to living with $>2$ smokers). There was a similar association between exposure and mortality from COPD (OR 2.51, 1.22 to 5.18), stroke (OR 2.08, 1.33 to 3.25) and ischaemic heart disease (OR 1.68, 1.05 to 2.68).

These studies add impetus to the demand for restrictions on smoking in public places. In the Hong Kong study deaths from poisoning were also analysed, as a control measure, and showed no relation to tobacco smoke exposure. Perhaps now there is an argument for reclassifying some of the other environmental tobacco related deaths as "poisoning"?

E Cetti

Specialist Registrar, Princess Royal Hospital, Haywards Heath, UK; ed_cetti@hotmail.com 